\title{
SISTEM TRACKING ONLINE PENGIRIMAN BARANG DAN DOKUMEN DI PT SCAM
}

\author{
Yusuf Agpal Nasution ${ }^{1}$, Harry Dhika ${ }^{2}$, Sri Rezeki ${ }^{3}$ \\ Fakultas Teknik, dan Ilmu Komputer Universitas Indraprasta PGRI. \\ Jl. Raya Tengah No. 80, Kel. Gedong, Kec. Pasar Rebo, Jakarta Timur 13760, telp/fax: (021) \\ 7818718 -78835283, email: kampus@unindra.ac.id \\ yusuf.agpal@gmail.com¹, dhikatr@yahoo.com², srirezeki104@gmail.com³
}

\begin{abstract}
Abstrak
Seiring dengan perkembangan gaya hidup masyarakat yang ingin cepat dan mudah, maka penggunaan website melalui jasa layanan online kini makin marak digunakan. Penelitian ini bertujuan untuk merancang dan membuat website untuk perusahaan ekspedisi yaitu PT. Surya Cipta Arte Media (SCAM). Melalui website ini, pengguna dapat mengakses informasi dan layanan yang ada pada perusahaan ekspedisi ini secara mudah dan cepat. Pengambilan barang serta pengantarannya dapat dilacak melalui web. Tujuan dari penelitian ini adalah untuk menganalisa kebutuhan operasional penjualan PT. Surya Cipta Arte Media (SCAM) dari segi sistem informasi lalu mengembangkan hal-hal yang masih dapat untuk dimaksimalkan bagi kebaikan perusahaan. Perancangan sistem ini dibangun diawali dengan analisa kebutuhan, selanjutnya dibangun dengan beberapa bahasa program berbasis web seperti HTML, CSS, Javascript, PHP, dan MySQL. Dalam proses pembangunannya melibatkan user dalam setiap tahapan, sehingga diharapkan sesuai dengan kebutuhan pemakai dan tujuan akhir.
\end{abstract}

Kata kunci: Web, System Tracking, SDLC,PHP,CSS.

\begin{abstract}
Along with the development of a community lifestyle that wants quick and easy. Then, the use of the website through online services is increasingly being used. This research aims to design and create a website for the expedition company namely PT. Surya Cipta Arte Media (SCAM). Through this website, users can access the information and services available to this expedition company easily and quickly. Pick-up and drop-off can be tracked through the web. The purpose of this research is to analyze the need for the operational Sales of PT. Surya CIPTA Arte Media (SCAM) in terms of information systems and then the things that can still be maximized for the good of the company. The design of the system was built starting with the need analysis, and then built with a few web-based programs such as HTML, CSS, Java script, PHP, and MYSQL. In the development process involves the user in each stage, so it is expected to meet the needs of the user and the final destination.
\end{abstract}

Keywords : Web, Tracking, SDLC,PHP,CSS.

\section{PENDAHULUAN}

Seiring dengan perkembangan zaman dibidang teknologi, perusahaan- perusahaan makin dipicu untuk menggunakan teknologi yang maju sebagai alat atau media untuk tetap bertahan dan memenangkan persaingan yang kian hari terasa ketat dan keras. Internet merupakan suatu media yang sudah tidak asing lagi diberbagai belahan dunia yang memiliki banyak fungsi. Akhir-akhir ini penggunaan internet yang menjurus kepada cyberspace kelihatannya akan mendominasi seluruh kegiatan di atas permukaan bumi dimasa kini dan masa datang dan secara umum akan berubah menjadi alat untuk persaingan antara perusahaan yang satu dengan yang lainnya. Ini pun akan membawa dampak yang sangat besar bagi perusahaan. Dampak pada aspek persaingan adalah terbentuk nya tingkat kompetisi yang semakin tajam. Globalisasi ekonomi juga membuat perubahan menjadi konstan, pesat, radikal, dan serentak. Sehingga perusahaan harus memiliki kemampuan yang cepat untuk beradaptasi terhadap perubahan yang terjadi sehingga perusahaan akan mampu bersaing dengan para kompetitornya.

Evolusi yang terjadi pada internet merupakan satu fenomena yang paling menarik dalam kemajuan teknologi yang terjadi sekarang. Satu aspek yang boleh dibilang utama dalam evolusi ini adalah munculnya electronic commerce (e-commerce) dalam lingkungan bisnis. E-commerce mengubah 
hampir semua fungsi bisnis area dan setiap kegiatannya, mulai dari transaksi jual belinya sampai periklanannya. Dengan lahirnya E-commerce ini memudahkan customer untuk dapat melakukan transaksi jual beli tanpa harus datang ketempatnya. Pelanggan akan dapat memperkirakan kapan harus memesan dan kapan pesanannya akan dikirimkan. Tidak hanya itu saja, keberadaan suatu website akan dapat memperluas jangkauan pemasaran perusahaan ini, maka diperlukan sebuah program aplikasi yang mendukung dalam proses pemasaran dan pemesanan.

Berdasarkan uraian pada latar belakang dan identifikasi masalah yang telah diajukan, maka permasalahan yang akan dikaji dalam penelitian ini dapat dirumuskan sebagai berikut bagaimana membuat sistem data online yang komunikatif dan informatif untuk PT. Surya Cipta Arte Media (SCAM), bagaimana merancang media informasi data online berbasis web pada PT. Surya Cipta Arte Media (SCAM), bagaimana pengujian media informasi pemesanan berbasis web pada PT. Surya Cipta Arte Media (SCAM) untuk memudahkan customer. Aplikasi ini membahas tentang seberapa efektif pelayanan terhadap customer PT. Surya Cipta Arte Media (SCAM).

\section{PENELITIAN RELEVAN}

Penelitian Relevan ini sangat menjadiacuan penting bagi peneliti agar dapat lebih mengenal tentang apa yang akan di teliti oleh peneliti, dan penelitian terdahulu ini sangat bermanfaat bagi peneliti. Berikut contoh Penelitian Relevan yang berkaitan dengan judul penelitian ini:

Penelitian oleh (Rizqy, 2016) yang berjudul "Sistem Tracking Mahasantri Berbasis Web Studi Kasus Pusat Ma'had Al-jami'ah Universitas Islam Negeri Maulana Malik Ibrahim Malang". Penelitian tersebut bertujuan untuk membangun sistem yang dapat digunakan sebagai alternative solusi untuk membantu tugas pengurus ma'has khususnya untuk mengetahui keberadaan mahasantri Pusat Ma'had Al-Jami'ah berdasarkan jadwal kegiatan, jadwal kuliah mahasantri (regular dan PPBA), dan data koordinat yang diperoleh dari integrasi sistem dan aplikasi mobile sistem ma'had.

Penelitian oleh (Nore, 2013) dalam penelitiannya yang berjudul "Perancangan Sistem Informasi Penjualan Dan Pemesanan Produk Berbasis Web", Penelitian tersebut bertujuan untuk membangun sistem informasi penjualan dan pemesanan berbasis web yang dapat mempermudah konsumen untuk melakukan pemesanan produk, lebih memperluas area pemasaran sehingga menambah jumlah konsumen, sebagai media informasi penjualan produk akan lebih komunikatif dan informative untuk promosi produk secara detail.

\section{METODE PENELITIAN}

Metode penelitian adalah cara ilmiah untuk mendapatkan data dengan tujuan dan kegunaan tertentu (Sugiyono, 2014). Metode yang digunakan yaitu metode kualitatif wawancara atau penelaahan dokumen. Metode kualitatif ini digunakan karena beberapa pertimbangan sebagai berikut :

1. Metode Wawancara

Peneliti melakukan tanya jawab dengaan supervisor gudang dan karyawan staff gudang PT. Surya Cipta Arte Media. Bapak Arif Muhammad Mansyur dalam wawancara dapat disimpulkan bahwa pada kenyataannya masih belum memaksimalkan fungsinya, karena dalam proses pencatatan persediaan barang masih menggunakan cara-cara manual dengan pencatatan pada kartu stock sehingga saat akan membuat laporan bulanan ataupun tahunan akan membutuhkan waktu yang lama.

2. Metode Observasi

Menurut (Syah, 2010) mengemukakan beberapa untuk observasi, yaitu: Observasi partisipasi, observasi tidak terstruktur, dan observasi kelompok. 
JRAMI (Jurnal Riset dan Aplikasi Mahasiswa Infarmatika)

Vol I No Q3 Tahun 2020

e-ISSN : 2715-8756

\section{HASIL DAN PEMBAHASAN \\ Diagram Alir Data (DAD) Sistem Yang Diusulkan}

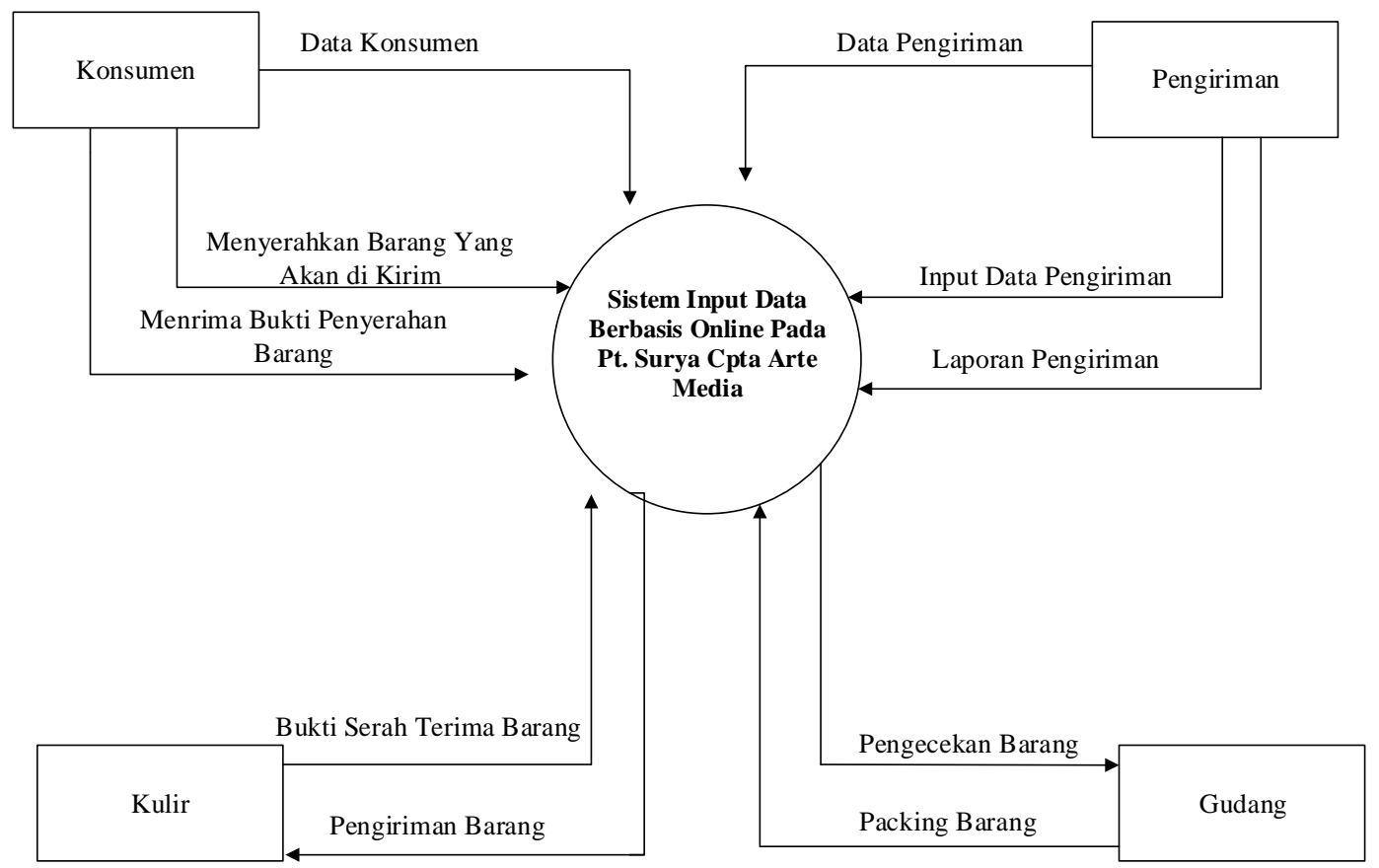

Gambar 1. Diagram Konteks Sistem Yang Diusulkan

\section{Normalisasi}

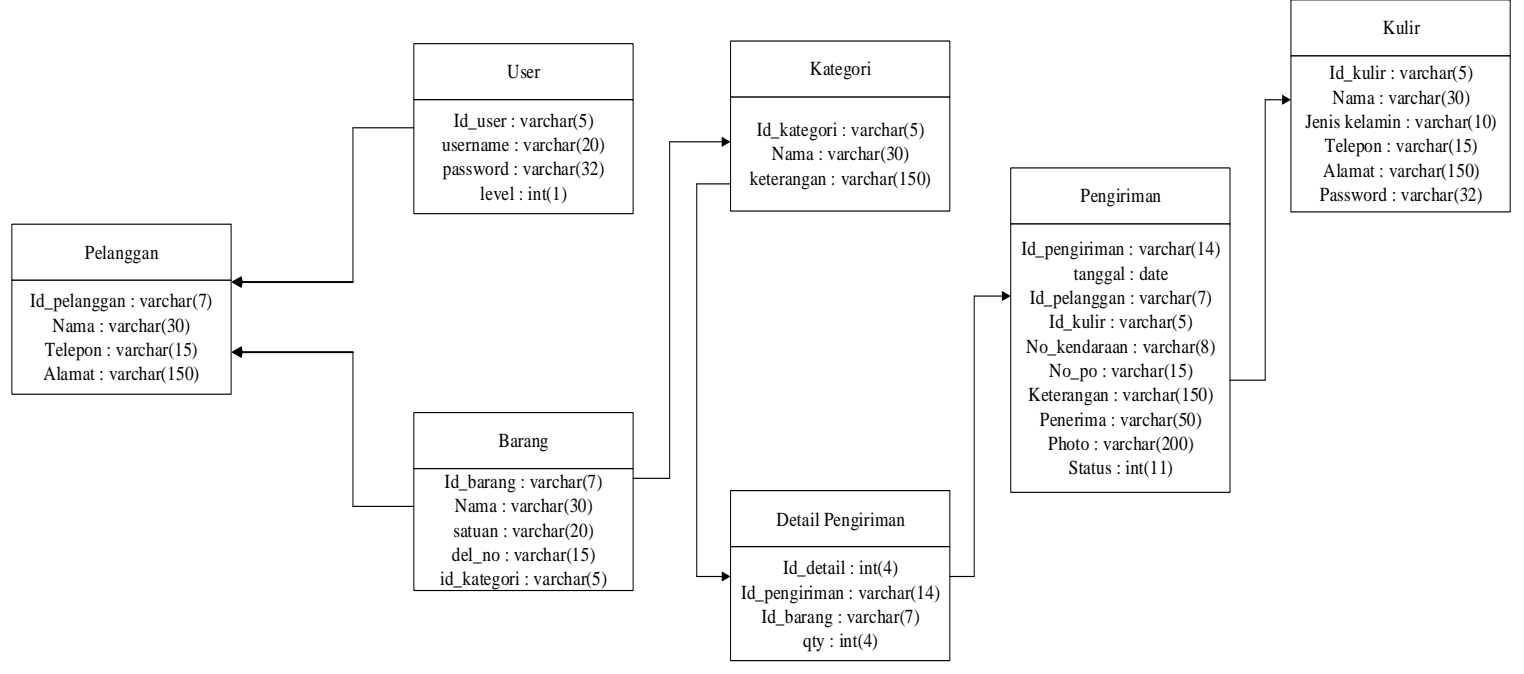

Gambar 2. Normalisasi Bentuk Ke-2 (NF) 


\section{Tampilan Layar}

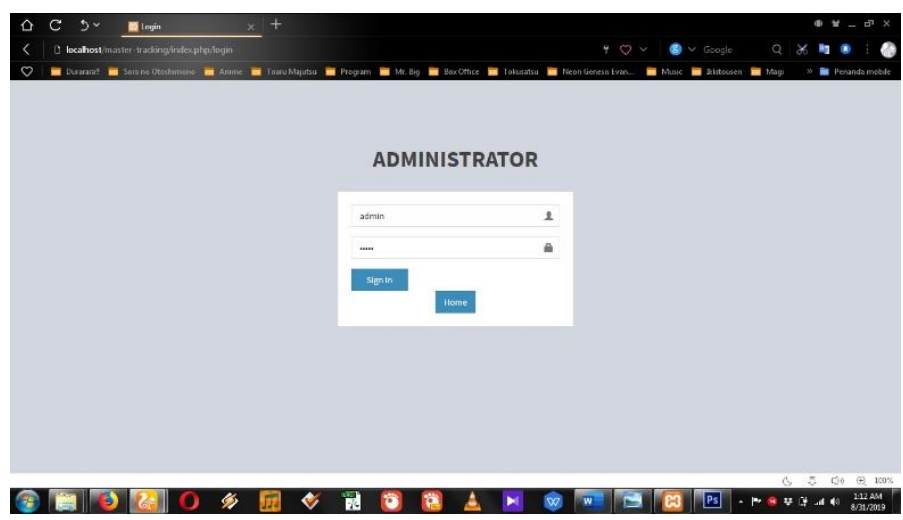

Gambar 3. Tampilan Halaman Login

Dihalaman ini tidak semua orang di perusahaan bisa mengaksesnya hanya admin tertentu dan atasan karena data semua langsung menuju ke sistem bagian atasan perusahaan.

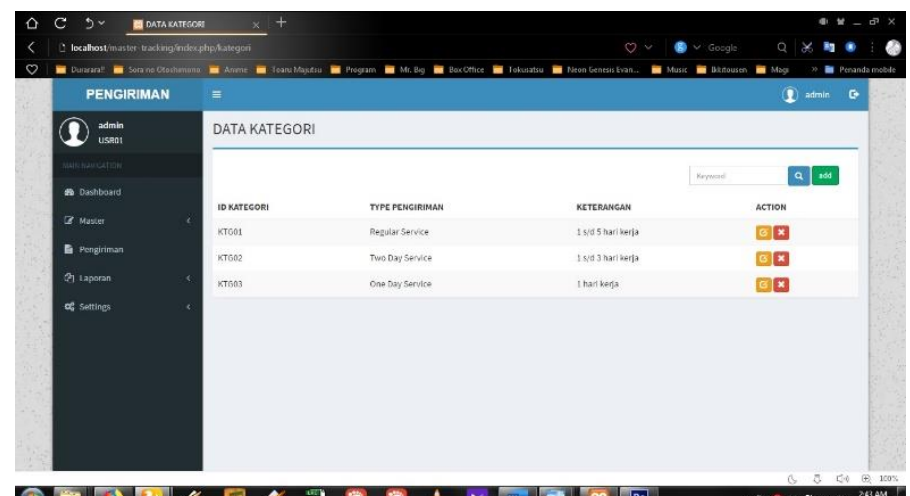

Gambar 4. Tampilan Halaman Data Kategori Pengiriman

Dihalaman Data Kategori Pengiriman ini konsumen sebelum melakukan pengisian form pengiriman barang konsumen ada di tampilkan data kategori pengirmannya sesuai dengan yang di inginkan.

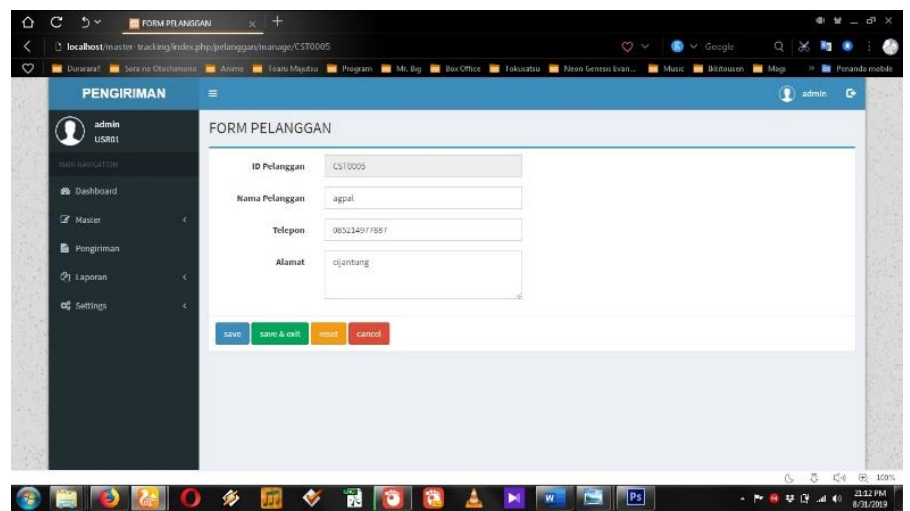

Gambar 5. Tampilan Halaman Data Pelanggan

Dihalaman ini konsumen akan di minta untuk mengisi data terlebih dahulu sebelum melakukan pengiriman barang setelah data tersimpan baru bisa melukan pengiriman 

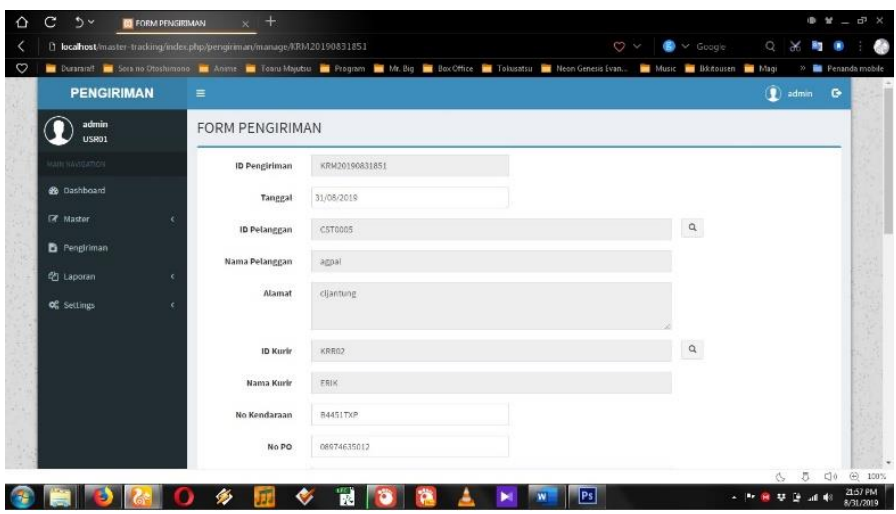

Gambar 6. Tampilan Halaman Form Pengiriman

Dihalaman ini konsumen akan mulai mendafatarkan pengirimannya dengan mengisi form pengiriman sesuai yang tertera di form dengan benar lalu save \& exit.

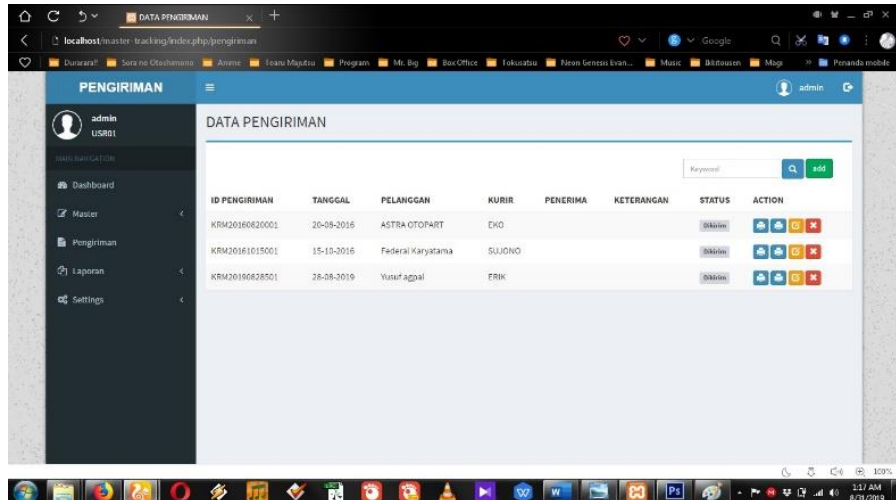

Gambar 7. Tampilan Halaman Data Pengiriman

Dihalaman ini konsumen akan di mulai di pandu oleh admin untuk memluai proses pengiriman dengan mengisi formnya terlebih dahulu.

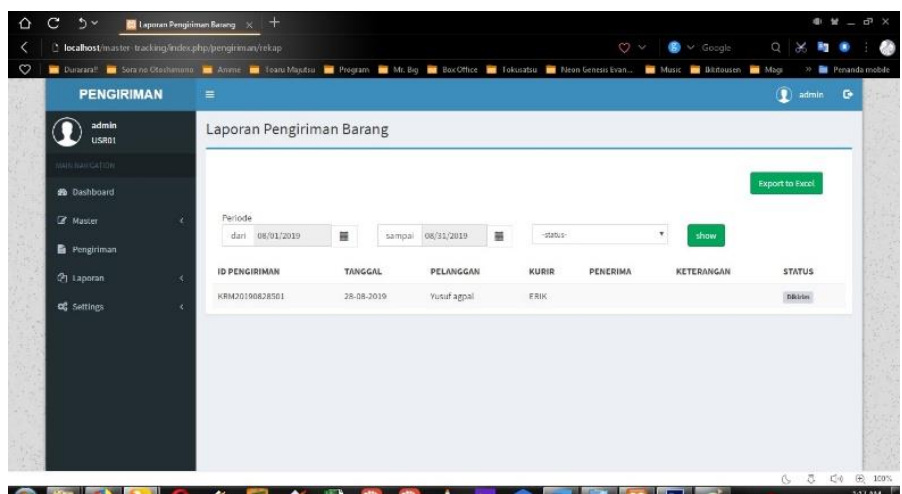

Gambar 8.Tampilan Halaman Laporan Pengiriman

Dihalaman ini data pendaftaran dari form pelanggan form barang sampai ke form pengiriman sudah masuk menjadi satu kedalam laporan pengiriman barang sesuai dengan yang di isi oleh konsumen sebelumnya 


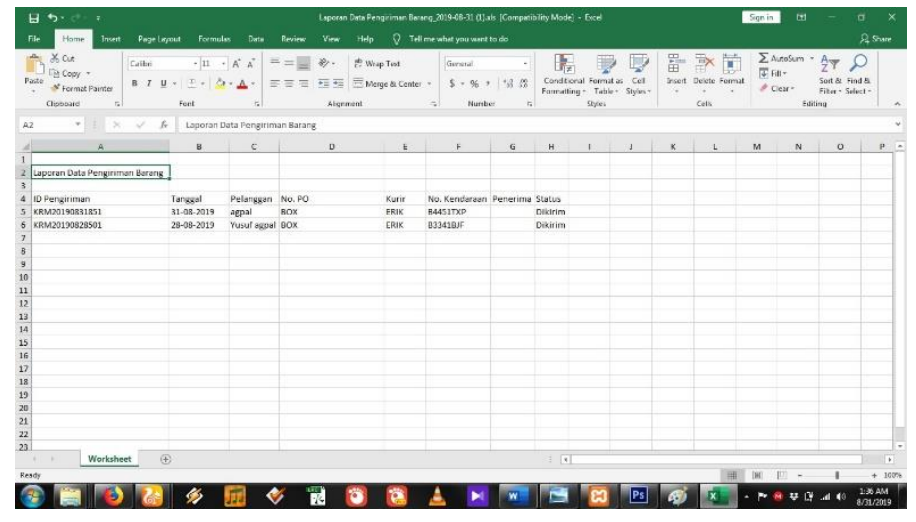

Gambar 9. Tampilan Halaman Laporan Pengiriman Export Excel

Tampilan Halaman Laporan Pengiriman Export Excel Di halaman ini data yang sudah tersimpan tadi bisa di lihat dengan offline dengan mengexport laporan pengirimannya ke bentuk excel dan dapat di simpan di handphone, $\mathrm{pc}$ ataupun tablet.

\section{SIMPULAN}

Berdasarkan uraian dan pembahasan bab - bab sebelumnya, maka dapat ditarik simpulan bahwa dari analisis sistem berjalan sesuai dengan apa yang di inginkan namun untuk kedepannya agar bisa lebih efektif lagi. Dengan permasalahan yang ada peneliti dapat membuat aplikasi penjualan berbasis web dan menggunakan MySQL sebagai media penyimpanan data. Aplikasi ini dapat digunakan untuk mengatasi permasalahan seperti input data pelayanan menjadi lebih cepat, penyampaian informasi pengiriman yang cepat serta proses transaksi yang lebih efektif, menyediakan tempat penyimpanan transaksi, laporan penjualan serta laporan pengiriman, yang sewaktu waktu dibutuhkan kembali sebagai bahan laporan.

\section{DAFTAR PUSTAKA}

Amaliya, Rizqy. (2016).Sistem Tracking Mahasantri Berbasis Web Studi Kasus Pusat Ma'had Al-jami'ah Universitas Islam Negeri Maulana Malik Ibrahim Malang," in Skripsi, p. 24.

Kadir, Abdul. (2014). Pengenalan Sistem Informasi Edisi Revisi, Edisi Revisi.

Nore, V. N. (2013). Perancangan Sistem Informasi Penjualan dan Pemesanan Produk Berbasis Web (Studi Kasus di CV. Richness Development Bandung, WIDYATAMA.

Sugiyono. (2014). Metode Penelitian Pendidikan Pendekatan Kuantitatif, Kualitatif, dan R\&D. Bandung: Alfabeta. Syah, Hidayat. 2010. Penelitian Deskriptif. Jakarta: Rajawali. 